\title{
CLASSIFICAÇÃO DAS ÁREAS DE RECARGA DO SISTEMA AQÜÍFERO GUARANI NO BRASIL EM DOMÍNIOS PEDOMORFOAGROCLIMÁTICOS - SUBSÍDIO AOS ESTUDOS DE AVALIAÇÃO DE RISCO DE CONTAMINAÇÃO DAS ÁGUAS SUBTERRÂNEAS
}

\author{
Marco Antônio Ferreira Gomes ${ }^{1}$ \\ Heloisa Ferreira Filizola ${ }^{2}$ \\ Cláudio A. Spadotto 3
}

\begin{abstract}
Resumo: O presente trabalho teve por objetivo classificar as áreas de recarga do Aqüífero Guarani, em território brasileiro, em porções definidas como Domínios Pedomorfoagroclimáticos, como subsídio aos estudos ambientais, sobretudo àqueles de avaliação de risco e de apoio à gestão sustentável destas áreas. Nesse sentido, foi adotada parte da proposta de AB'SABER (1970) - Domínios Morfoclimáticos, em combinação com parte da proposta de RESENDE et al. (1995) - Domínios Pedobioclimáticos, incorporando o uso agrícola que satisfaz o princípio do tetraedro ecológico e das variáveis necessárias aos estudos de avaliação de risco ambiental. A metodologia de classificação dos domínios obedeceu às diferenças existentes entre as variáveis solo, morfologia, uso agrícola e clima, por região ou estado, caracterizadas por valores médios ou informações mais representativas. Os resultados obtidos permitiram a divisão da área em oito domínios, com subdivisões em alguns casos, com inferências sobre uma caracterização preliminar de riscos.
\end{abstract}

Palavras-chave: Estudos ambientais; Área de recarga; Risco de contaminação; Sistema Aqüífero Guarani.

\section{Introdução}

As áreas de recarga direta ou de afloramento do Sistema Aqüífero Guarani têm se mostrado bastante expostas ao risco de degradação, seja por agrotóxicos, seja por processos erosivos, principalmente pelo avanço das atividades agrícolas sobre elas, sem muito critério em relação à capacidade de uso das mesmas. Esse cenário, comum no Brasil, aliado à alta vulnerabilidade natural das áreas de recarga do aqüífero em questão, colocamnas em situação de alta exposição ao risco de contaminação do lençol freático como também favorece a formação de ravinas e voçorocas, principalmente como conseqüência de práticas agrícolas inadequadas. Trabalhos realizados pela Embrapa Meio Ambiente nessas áreas (EMBRAPA, 1999; EMBRAPA, 2001; GOMES et al., 1996; GOMES et al., 2001; PESSOA et al., 1998; PESSOA et al., 1999), particularmente na região de Ribeirão Preto/SP, no período compreendido entre 1994 e 2001 evidenciaram que as atividades agrícolas utilizam uma carga considerável de produtos químicos potencialmente contaminantes, destacando-se alguns herbicidas usados intensivamente na cultura de cana-de-açúcar. Outras regiões de recarga do Aqüífero Guarani nos Estados de Goiás (culturas de milho e de soja), de Mato Grosso (cultura de soja), Mato Grosso do Sul (cultura de soja), Paraná (cultura de milho), Santa Catarina (cultura de maçã) e Rio Grande do Sul (cultura de arroz), também exibem cenários de risco de contaminação para a água subterrânea. Este trabalho tem como objetivo uma proposta de classificação das áreas de recarga do aqüífero em Domínios Pedomorfoagroclimáticos nos estados citados acima e uma avaliação do risco (baixo, médio e alto) de contaminação dos mesmos, tendo como referencial o padrão de presença dos agrotóxicos mais usados nas culturas predominantes em cada domínio aqui exposto. Pelo fato do Estado de Minas Gerais ter

\footnotetext{
1 Geólogo, Doutor em Solos e Nutrição de Plantas, Pesquisador da Embrapa Meio Ambiente, Jaguariúna/SP. (e-mail: Gomes@cnpma.embrapa.br).

${ }^{2}$ Geógrafa, Doutora em Ciências da Terra, Pesquisadora da Embrapa Meio Ambiente, Jaguariúna/SP. (e-mail: filizola@cnpma.embrapa.br).

${ }^{3}$ Eng. Agrônomo, Ph.D. Ciência de Solo e Água, Pesquisador da Embrapa Meio Ambiente, Jaguariúna/ SP. (e-mail: spadotto@cnpma.embrapa.br).
} 
uma área de recarga muito restrita $\left(450 \mathrm{~km}^{2}\right)$ ocupada por pastagem, o mesmo não foi incorporado ao presente trabalho.

\section{Material e método}

0 método de trabalho consistiu no levantamento das informações existentes sobre as áreas de recarga do Sistema Aqüífero Guarani no Brasil, abrangendo as características geológicas, de solos, relevo, uso agrícola e clima. Inicialmente, foram obtidas informações sobre geologia para a delimitação da extensão e dos limites da área de recarga na escala 1:250.000 (RADAMBRASIL, 1984; ARAÚJO et al., 1995; CAMPOS, 2000). 0 procedimento seguinte foi a avaliação da área de recarga por estado, com identificação dos principais tipos de solos na escala $1: 250.000$ e de relevo na escala 1:1.000.000 (RADAMBRASIL, 1984). As informações sobre o uso atual do solo (vegetação natural e culturas) foram retiradas de imagens de satélite (LANDSAT, 2002) e de observações in loco. Os dados climáticos, precipitação e temperatura foram obtidos de fontes diversas, citadas nas tabelas apresentadas ao longo do texto. Para a delimitação dos Domínios Pedomorfoagroclimáticos foi adotada parte da proposta de AB'SABER (1970), Domínios Morfoclimáticos, em combinação com parte da proposta de RESENDE et al. (1995), Domínios Pedobioclimáticos, incorpo-rando a estas o uso agrícola que satisfaz o princípio do tetraedro ecológico e das variáveis necessárias aos estudos de avaliação de risco ambiental para cada domínio. 0 conjunto de informações obtidas e integradas no Spring (SIG desenvolvido pelo INPE) por região ou domínio, possibilitou a classificação, conforme consta das tabelas 1 a 7.

\section{Resultados e discussão}

Os resultados obtidos contemplam oito Domínios Pedomorfoagroclimáticos para as áreas de recarga do Sistema Aqüífero Guarani no Brasil (Fig. 1), conforme descrição a seguir:

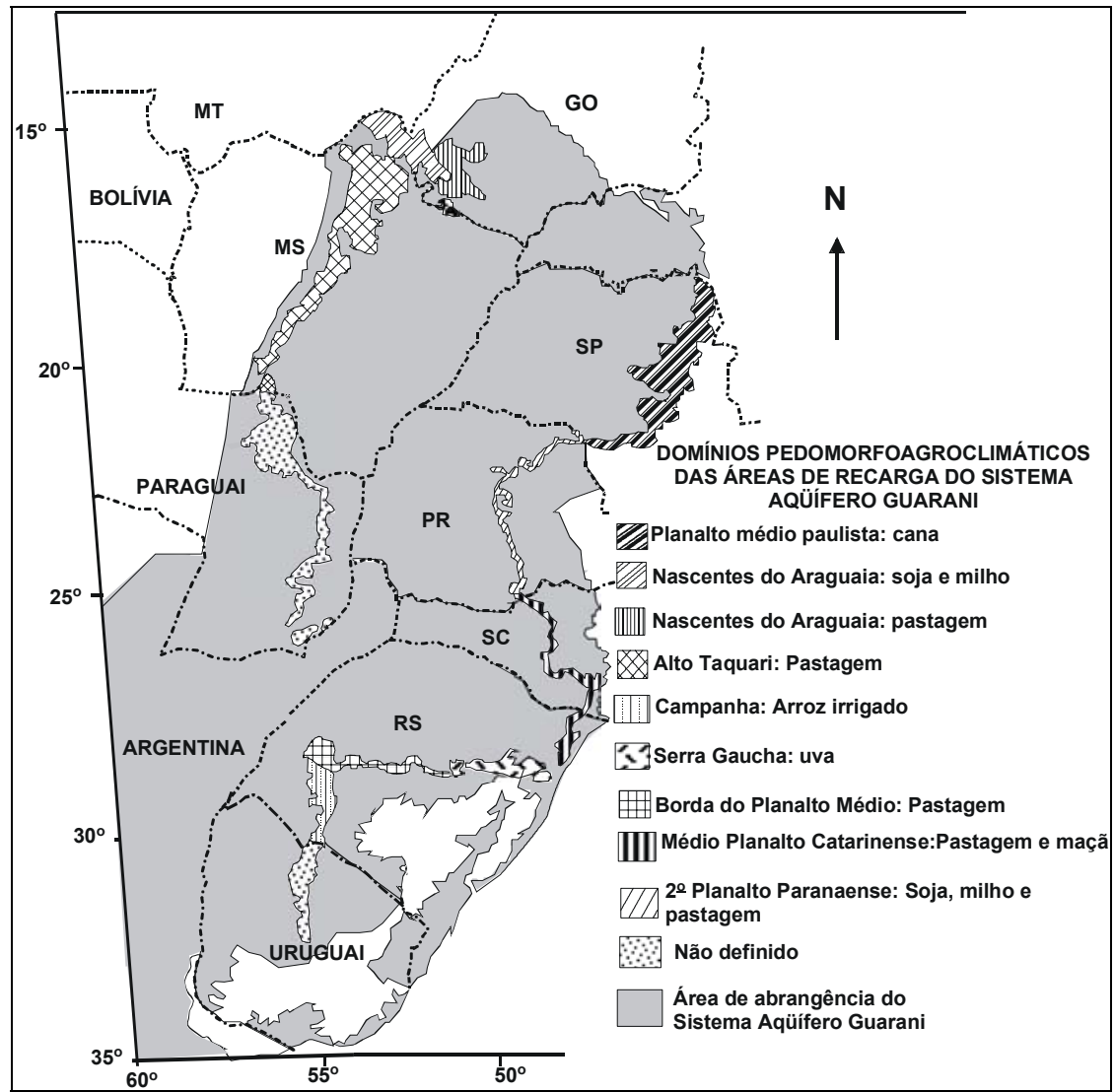

Figura 1 Domínios pedomorfoagroclimáticos das áreas de recarga do Aqüífero Guarani no território brasileiro. Adaptado de ARAUJO et al. (1997). 
Domínio Pedomorfoagroclimático das áreas de recarga do Aqǘf́ero Guarani no Estado de São Paulo

A área de recarga do Aqüiffero Guarani no Estado de São Paulo abrange cerca de $16.000 \mathrm{~km}^{2}$, ocupando uma faixa de norte a sul do estado localizada na porção Centro-Oeste, inserido nas coordenadas $21^{\circ}$ e $23^{\circ}$ de latitude sul e $47^{\circ}$ e $50^{\circ}$ de longitude oeste.

Devido a algumas diferenças quanto ao tipo de cultura, foi feita uma subdivisão em três regiões ou faixas de recarga, mas que não caracteriza uma subdivisão em domínios: faixa de recarga da porção Centro-Norte, com os seguintes municípios: Franca, Batatais, Brodosqui, Altinópolis, Cajuru, Serrana, Ribeirão Preto, Cravinhos, São Simão e Luís Antônio; faixa de recarga da porção Central, com os seguintes municípios: Araraquara,
Corumbataí, São Carlos, Ibaté, Analândia, Itirapina, Brotas, Bocaina, Dois Córregos, Boa Esperança do Sul, Bariri, São Pedro, Águas de São Pedro, Santa Maria da Serra, São Manuel e Botucatu; faixa de recarga da porção Centro-Sul, com os seguintes municípios: Pardinho, Bofete, Torre de Pedra, Paranapanema, Avaré, Itaí e Tejupá. A Tab. 1 mostra as principais características de clima, solo e cultivos em cada um dos três domínios identificados. 0 aspecto morfológico não foi ressaltado pela semelhança em toda extensão, estando toda a faixa de recarga inserida no Planalto Médio Paulista, nome também dado ao Domínio Pedomorfoagroclimático do Estado de São Paulo. Todavia, o relevo varia de ondulado a fortemente ondulado em toda a extensão dessas áreas.

Tabela 1 Características de solos, climáticas e tipos de culturas predominantes nas três faixas que compõem os Domínios Pedomorfoagroclimático das áreas de recarga do Aqüífero Guarani no Estado de São Paulo.

\begin{tabular}{c|c|c|c|c|c}
\hline $\begin{array}{c}\text { Domínio Pedomorfo- } \\
\text { agroclimático }\end{array}$ & Faixas & Solos & $\begin{array}{c}\text { Culturas } \\
\text { predominantes }\end{array}$ & $\begin{array}{c}\text { Precipitação Média } \\
\text { Anual }{ }^{*}(\mathrm{~mm})\end{array}$ & $\begin{array}{c}\text { Temperatura Média } \\
\left.\text { Anual }{ }^{\circ} \mathrm{C}\right)\end{array}$ \\
\hline \multirow{5}{*}{ Planalto Médio Paulista } & Faixa Centro-norte & $\begin{array}{c}\mathrm{LVq} \\
\mathrm{RQ}\end{array}$ & Cana-de-açúcar & 22,4 \\
\cline { 2 - 6 } & Faixa Central & $\begin{array}{c}\mathrm{RQ} \\
\mathrm{PVq}\end{array}$ & $\begin{array}{c}\text { Cana-de-açúcar, citros, arroz } \\
\text { irrigado e pastagem }\end{array}$ & 1550 \\
\cline { 2 - 5 } & Faixa Centro-sul & $\mathrm{RQ}$ & $\begin{array}{c}\text { Cana-de-açúcar e } \\
\text { pastagem }\end{array}$ & 21,6 \\
\hline
\end{tabular}

Fontes: *Estação do IAC - Ribeirão Preto, ESALQ-Piracicaba e UNESP- Botucatu, referentes ao período 1990-1998.

$\mathrm{LVq}$ - Latossolo Vermelho psamítico; RQ - Neossolo Quartzarênico; PVq - Argissolo Vermelho de textura média

(IAC, 1991; MIKLÓS e GOMES, 1996).

Domínio Pedomorfoagroclimático das áreas de recarga do Sistema Aqüífero Guarani no Estado de Goiás

A área de afloramento do Aqǘfero Guarani no Estado de Goiás abrange cerca de $12.000 \mathrm{~km}^{2}$, estando grande parte dessa área distribuída ao longo da região que abrange as nascentes do rio Araguaia, na divisa dos Estados de Goiás e Mato Grosso entre os paralelos $17^{\circ} 00^{\prime}$ e $20^{\circ} 00^{\prime} \mathrm{S}$ e os meridianos $51^{\circ} 30^{\prime} \mathrm{e} 55^{\circ} 30^{\prime} \mathrm{O}$. Devido à grande uniformidade, tanto de uso agrícola quanto dos aspectos climáticos, foi definida a existência de um único domínio pedomorfoagroclimático denominado Nascentes do Araguaia, conforme descrição contida na Tab. 2.

Tabela 2 Características climáticas e tipos de culturas predominantes no domínio pedomorfoagroclimático das áreas de recarga do Aqüifero Guarani no Estado de Goiás.

\begin{tabular}{c|c|c|c|c}
\hline Domínio Pedomorfoagroclimático & Solo & $\begin{array}{c}\text { Cultura } \\
\text { predominante }\end{array}$ & $\begin{array}{c}\text { Precipitação Média } \\
\text { Anual }{ }^{*}(\mathrm{~mm})\end{array}$ & $\begin{array}{c}\text { Temperatura Média } \\
\text { Anual }^{*}\left({ }^{\circ} \mathrm{C}\right)\end{array}$ \\
\hline Nascentes do Araguaia & $\mathrm{RQ}$ & Soja e pastagem & 1863 \\
\hline
\end{tabular}

Fonte: *Mosteiro Beneditino (Mineiros-GO) no período de 1995 a 2000.

\section{Domínio Pedomorfoagroclimático das áreas de recarga do Sistema Aqüífero Guarani na porção leste do Estado de Mato Grosso}

No Estado de Mato Grosso foi considerada apenas a região de Alto Garças que mantém uma interligação entre a área de abrangência do rio Araguaia e a área de afloramento do aqüifero
Guarani localizada na divisa dos Estados de Mato Grosso e Mato Grosso do Sul. A área de afloramento nessa região é de cerca de $6.500 \mathrm{~km}^{2}$, estando situada entre os paralelos $16^{\circ} 40^{\prime}$ e $17^{\circ} 00^{\prime} \mathrm{S} \mathrm{e}$ os meridianos $53^{\circ} 30^{\prime} \mathrm{e} 54^{\circ} 00^{\prime} \mathrm{O}$. Os dados contidos na Tab. 3 expressam suas características que, pela semelhança e proximidade, também se insere no Domínio Nascentes do Araguaia. 
Tabela 3 Características climáticas e tipos de culturas predominantes no Domínio Pedomorfoagroclimático das áreas de recarga do Aqüifero Guarani na porção leste do Estado de Mato Grosso.

\begin{tabular}{c|c|c|c|c}
\hline Domínio Pedomorfoagroclimático & Solos & $\begin{array}{c}\text { Cultura } \\
\text { predominante }\end{array}$ & $\begin{array}{c}\text { Precipitação } \\
\text { Média Anual }{ }^{*}(\mathrm{~mm})\end{array}$ & $\begin{array}{c}\text { Temperatura Média } \\
\text { Anual }{ }^{*}\left({ }^{\circ} \mathrm{C}\right)\end{array}$ \\
\hline Nascentes do Araguaia & $\begin{array}{c}\mathrm{RQ} \\
\mathrm{LVq}\end{array}$ & Soja/milho & 1830 a 2130 & 22,3 \\
\hline
\end{tabular}

Fonte: *EMPA-MT no período de 1994-1998.

\section{Domínio Pedomorfoagroclimático das áreas de recarga do Sistema Aqüífero Guarani no Estado de Mato Grosso do Sul}

A área de afloramento do aqüífero Guarani mais importante no Estado de Mato Grosso do Sul representa cerca de $27.800 \mathrm{~km}^{2}$, localizada na região nordeste e parte da região sudoeste, entre as latitudes $17^{\circ} 00^{\prime}$ e $20^{\circ} 00^{\prime}$ Sul e as longitudes $53^{\circ} 00^{\prime}$ e $55^{\circ} 00^{\prime}$ Oeste, abrangendo em quase toda sua extensão a bacia hidrográfica do Alto Taquari. Esta é composta basicamente pelos rios Taquari, ao norte, e Coxim na porção sudoeste-oeste da área. Entre os municípios mais importantes estão São Gabriel D'oeste, Coxim, Camapuã, Alcinópolis e Pedro Gomes. Existe, ainda, outra porção situada a oeste de Campo Grande e que se estende até o Paraguai. Devido à predominância de um único padrão pedomorfoagroclimático, considerando somente as áreas de recarga direta ou de afloramento do Aqüifero Guarani, com diferença apenas entre vegetação/pastagem nativa e pastagem cultivada, foi definido apenas um domínio denominado de Alto Taquari, conforme descrição contida na Tab. 4.

Tabela 4 Características climáticas e tipos de culturas predominantes no Domínio Pedomorfoagroclimático do Alto Taquari, Estado de Mato Grosso do Sul.

\begin{tabular}{c|c|c|c|c}
\hline Domínio Pedomorfoagroclimático & Solo & $\begin{array}{c}\text { Culturas } \\
\text { predominantes }\end{array}$ & $\begin{array}{c}\text { Precipitação Média } \\
\text { Anual }{ }^{*}(\mathrm{~mm})\end{array}$ & $\begin{array}{c}\text { Temperatura Média } \\
\text { Anual }{ }^{*}\left({ }^{\circ} \mathrm{C}\right)\end{array}$ \\
\hline \multirow{2}{*}{ Alto Taquari } & \multirow{2}{*}{$\mathrm{RQ}$} & Pastagem nativa & \multirow{2}{*}{1460} & 23,5 \\
\cline { 2 - 3 } & & Pastagem cultivada & & \\
\hline
\end{tabular}

Fonte: *COINTA. Média de 5 anos (1996-2000), considerando medidas realizadas em Coxim (MS).

\section{Domínio Pedomorfoagroclimático das áreas de recarga do Sistema Aqüífero Guarani no Estado do Paraná}

A área de afloramento do Aqüífero Guarani no Estado do Paraná abrange cerca de $2.150 \mathrm{~km}^{2}$, distribuída ao longo de uma faixa estreita a oeste de Curitiba, com extensão de norte a sul. Os municípios mais importantes localizados nessas áreas são Jacarezinho, Santo Antônio da Platina, Cândido Abreu, Ortigueira, Ivaiporã, Pitanga, Guarapuava, e União da Vitória na divisa com Santa Catarina.

Em razão da existência de duas condições predominantes de uso agrícola e uma pequena variação climática, principalmente precipitação, foram definidas duas faixas de domínio: faixa centro-norte e faixa centro-sul, integrantes do Médio Planalto Paranaense, conforme os dados contidos na Tab. 5

Tabela 5 Características climáticas e tipos de culturas predominantes no Domínio Pedomorfoagroclimático das áreas de recarga do Aqüífero Guarani no Estado do Paraná.

\begin{tabular}{c|c|c|c|c|c}
\hline Domínio Pedomorfoagroclimático & Faixas & Solos & $\begin{array}{c}\text { Culturas } \\
\text { predominantes }\end{array}$ & $\begin{array}{c}\text { Precipitação Média } \\
\text { Anual }{ }^{*}(\mathrm{~mm})\end{array}$ & $\begin{array}{c}\text { Temperatura Média } \\
\text { Anual }{ }^{*}\left({ }^{\circ} \mathrm{C}\right)\end{array}$ \\
\hline \multirow{2}{*}{$2^{\circ}$ Planalto Paranaense } & Centro-norte & $\mathrm{RQ}$ & Pastagem & 1380 & 19,0 \\
\cline { 2 - 6 } & Centro-sul & $\mathrm{PVq}$ & $\begin{array}{c}\text { Soja/milho e } \\
\text { pastagem }\end{array}$ & 1300 \\
\hline
\end{tabular}

Fonte: *IAPAR (2002).

$\mathrm{RQ}$ - Neossolo Quartzarênico; PVq - Argissolo Vermelho de textura média. 
Domínio Pedomorfoagroclimático das áreas de recarga do Sistema Aqǘfero Guarani no Estado de Santa Catarina

No Estado de Santa Catarina a área de afloramento do Aqǘfero Guarani é cerca de $1.780 \mathrm{~km}^{2}$, abrangendo os municípios da região de Lages.

A porção de recarga nesse estado apresenta uma faixa bastante delgada, tendo em alguns locais menos de um quilômetro de largura. Em razão da uniformidade de uso agrícola, dominantemente pastagem, como também de outros aspectos ambientais, tais como solo, relevo e clima, foi definido apenas um domínio para o Estado de Santa Catarina, caracterizado por Médio Planalto Catarinense, considerando a mesma nomenclatura usada para as características morfológicas. A Tab. 6, a seguir, sintetiza as informações gerais deste domínio.

Tabela 6 Características climáticas e tipos de culturas predominantes no Domínio Pedomorfoagroclimático das áreas de recarga do Aqüífero Guarani no Estado de Santa Catarina.

\begin{tabular}{c|c|c|c|c}
\hline Domínio Pedomorfoagroclimático & Solos & $\begin{array}{c}\text { Culturas } \\
\text { predominantes }\end{array}$ & $\begin{array}{c}\text { Precipitação Média } \\
\text { Anual }{ }^{*}(\mathrm{~mm})\end{array}$ & $\begin{array}{c}\text { Temperatura Média } \\
\text { Anual }{ }^{*}\left({ }^{\circ} \mathrm{C}\right)\end{array}$ \\
\hline Médio Planalto Catarinense & $\mathrm{RQ}$ & $\begin{array}{c}\text { Pastagem } \\
\text { Maçã }\end{array}$ & 1250 & 17,5 \\
\hline
\end{tabular}

Fonte: *EPAGRI (1997) e INSTITUTO DE PLANEJAMENTO E ECONOMIA AGRÍCOLA (1999).

$R Q$ - Neossolo Quartzarênico; PVq - Argissolo Vermelho de textura média.

\section{Domínios Pedomorfoagroclimáticos das áreas de recarga do Sistema Aqǘfero Guarani no Estado do Rio Grande do Sul}

A área de afloramento do Aqüifero Guarani no Estado do Rio Grande do Sul possui cerca de $37.320 \mathrm{~km}^{2}$, distribuída ao longo de uma faixa delgada de leste a oeste do Estado, com inflexão para o sul até a divisa com o Uruguai, adentrando nesse país por dezenas de quilômetros. Essa faixa encontra-se inserida nas coordenadas $29^{\circ} 00^{\prime}$ e $30^{\circ} 00^{\prime}$ de Latitude Sul e $50^{\circ} 30^{\prime}$ e $55^{\circ} 40^{\prime}$ de Longitude Oeste, envolvendo três domínios pedomorfoagroclimáticos denominados de Serra Gaúcha/Encosta Inferior Nordeste; Borda do Planalto Médio/Missões e Campanha. 0 clima predominante é subtropical úmido, sem estiagem. Em geral, a temperatura do mês mais quente é superior a $22^{\circ} \mathrm{C}$ e a do mês menos quente varia de 3 a $18^{\circ} \mathrm{C}$.
As principais cidades ao longo das áreas de recarga estão assim distribuídas: Serra Gaúcha/encosta nordeste - Portão, Novo Hamburgo, São Leopoldo, Parobé, Taquara e Santo Antônio da Patrulha; Borda do Planalto Médio/Missões - Santa Maria, Santiago, São Pedro do Sul, Jaguarí e São Francisco de Assis; Campanha - Alegrete, Rosário do Sul e Santana do Livramento. A Tab. 7 a seguir sintetiza as informações relativas a esses domínios.

A integração das informações acima possibilitou a classificação das áreas de recarga do Sistema Aqüifero Guarani em Domínios Pedomorfoagroclimáticos, conforme a metodologia apresentada, partindo-se dos domínios propostos por AB'SABER (1970) e REZENDE et al. (1995), acrescidos dos tipos de solos, mais especificamente a textura, além dos tipos de atividades agrícolas dominantes.

Tabela 7 Características climáticas e tipos de culturas predominantes nos diferentes Domínios Pedomorfoagroclimáticos das áreas de recarga do Aqüífero Guarani no Estado do Rio Grande do Sul.

\begin{tabular}{c|c|c|c|c}
\hline Domínio Pedomorfoagroclimático & Solos & $\begin{array}{c}\text { Culturas } \\
\text { predominantes }\end{array}$ & $\begin{array}{c}\text { Precipitação Média } \\
\text { Anual }{ }^{*}(\mathrm{~mm})\end{array}$ & $\begin{array}{c}\text { Temperatura Média } \\
\text { Anual }{ }^{*}\left({ }^{\circ} \mathrm{C}\right)\end{array}$ \\
\hline $\begin{array}{c}\text { Serra Gaúcha/ } \\
\text { encosta inferior nordeste }\end{array}$ & $\mathrm{CXve}$ & Uva & 2.470 & $<18$ \\
\hline Borda do Planalto Médio/ Missões & $\mathrm{PVq}$ & Pastagem & 2.000 & 18 a 22 \\
\hline Campanha & $\mathrm{RQ} \mathrm{e} \mathrm{PVq}$ & $\begin{array}{c}\text { Arroz Irrigado/ } \\
\text { pastagem }\end{array}$ & 1.190 & 20 a 24 \\
\hline
\end{tabular}


A informação agrícola sobre o uso do solo em cada domínio permitiu distinguir as culturas que utilizam uma quantidade maior de agrotóxicos, como a cana, a soja e o milho. Os dados de precipitação e temperatura foram usados como fatores interferentes no processo de deslocamento no perfil do solo dos produtos químicos aplicados no controle de pragas e doenças. Assim, com a integração dessas informações, foi elaborado 0 mapa de risco de contaminação do aqǘfero Guarani, apresentado na Fig. 2. As particularidades de cada região ou estado, envolvendo diferentes usos agrícolas, clima, relevo e solos, possibilitaram a obtenção dos domínios ora propostos, importantes nos estudos regionais de avaliação de riscos.

Este mapa poderá servir de orientação não só para estudos de abrangência regional, mas também de interesse local, principalmente em relação à tomada de decisão quanto à necessidade de estudos pontuais ou mesmo de procedimentos de intervenção.

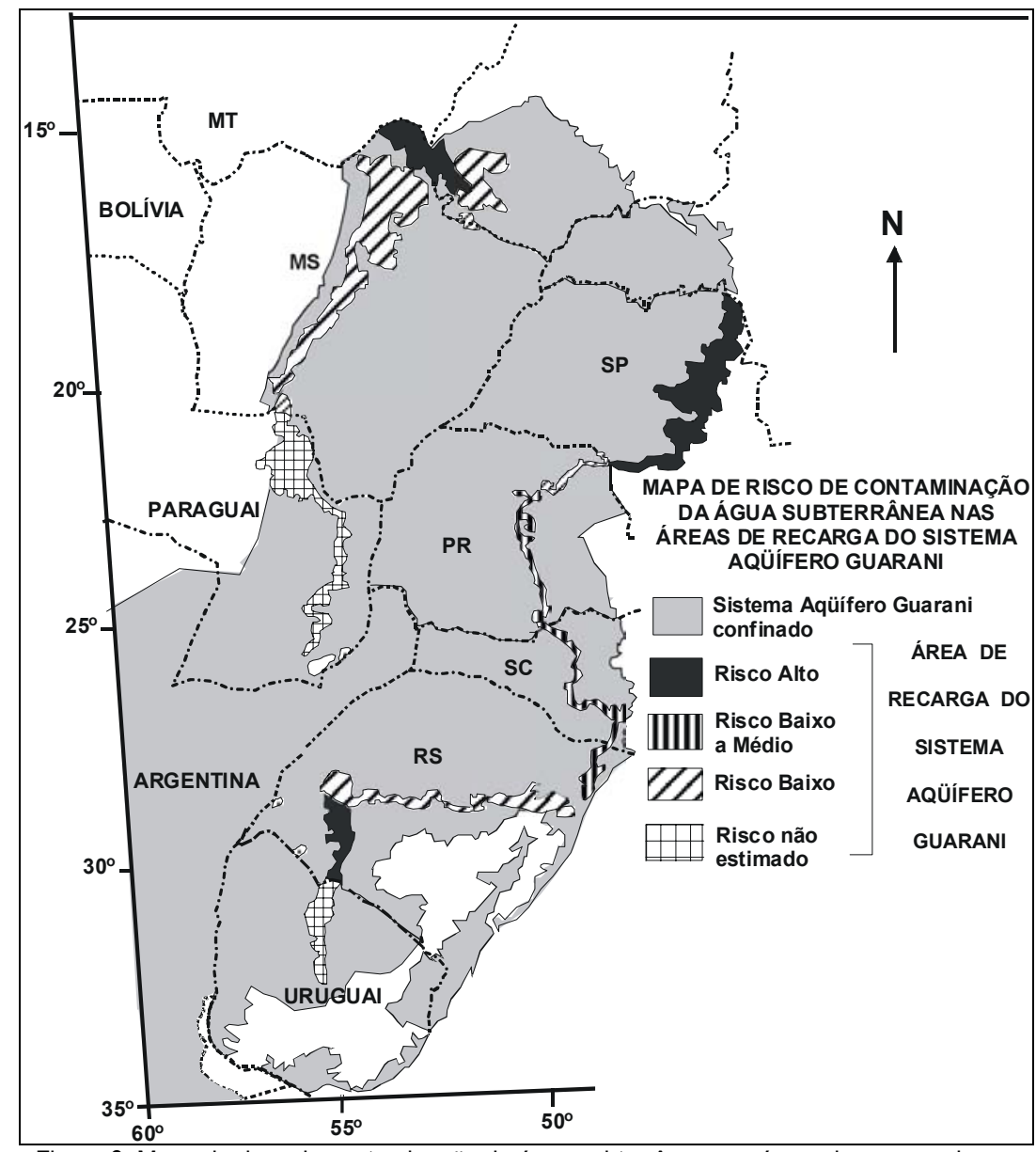

Figura 2 Mapa de risco de contaminação da água subterrânea nas áreas de recarga do Aqüífero Guarani em território brasileiro. Adaptado de ARAUJO et al. (1997).

\section{Conclusão}

A classificação das áreas de recarga do Sistema Aqüífero Guarani no Brasil resultou na obtenção de oito Domínios Pedomorfoagroclimáticos (Fig. 1), importantes no direcionamento de estudos que envolvam a interface agricultura e meio ambiente. A classificação das áreas de risco permite uma orientação, ainda que preliminar, quanto à escolha de porções potencialmente mais críticas (Fig. 2) para estudos específicos em escala de maior detalhe e mesmo para intervenção imediata naquelas identificadas como "piores casos" (worst case), como nas áreas do domínio "Nascentes do Araguaia" cultivadas com milho sorgo, do "Planalto Médio Paulista", cultivadas com cana-de-açúcar e, do domínio da "Campanha", cultivadas com arroz irrigado. Tais domínios representam cenários potencialmente críticos, dada a grande quantidade de agroquímicos usados nessas culturas. 
GOMES, M.A.F.; FILIZOLA, H.F.; SPADOTTO, C.A. (2006). Classification of recharge areas of Guarani Aquifer in Brazil in pedomorphoagroclimatics domains - subsidy for studies of contamination risk evaluation of groundwater. Revista do Departamento de Geografia, $\mathrm{n}$. 18, p. 67-74.

Abstract: The recharge portion of Guarani Aquifer has more than $100.000 \mathrm{~km}^{2}$ in the Brazilian country, which is comprised by eight states with their particularities. The aim of this work is to classify recharge area of the Guarani Aquifer's as Pedomorphoagroclimatics Domains to subsidize environmental studies, over all the ones related to risk evaluation and sustainable management of areas. The two methodologies Morphoclimatic Domain (AB'SABER, 1970) and Pedobioclimatic Domain (RESENDE et al., 1995) were jointed and adopted as a new concept. Considering agricultural uses, this procedure allows to consider the ecological tetrahedron purposes and the selected parameters commonly used in studies for environmental risk evaluation. For each region or state, the classification in domains considered differences among the physical variables, soil, morphology, agriculture activity and climate, which were taken as mean values or the most representative information. The results showed a stratification of the area in eight different domains, with subdivisions in some cases, making possible inferences about an incipient risk characterization.

Keywords: Pedomorphoagroclimatic Domain, Recharge area, Groundwater contamination, Guarani Aquifer.

Recebido em 3 de março de 2005, aceito em 2 de outubro de 2005.

\section{Referências}

AB'SABER. A.N. (1970) Províncias geológicas e domínios morfoclimáticos no Brasil. São Paulo, Geomorfologia, (20): $26 \mathrm{p}$.

ARAÚJO, L.M.; FRANÇA, A.B.; POTTER, P.E. (1995) Aqüifero gigante do Mercosul no Brasil, Argentina, Paraguai e Uruguai: mapas hidrogeológicos das Formações Botucatu, Pirambóia, Rosário do Sul, Buena Vista, Misiones e Tacuarembó. UFPR/Petrobrás, Curitiba, 16. (9 mapas).

CAMPOS, H.C.N.S. (2000) Modelación Conceptual y Matemática Del Acuífero Guarani, Cono Sur. Acta Geológica Leopoldensia/ estudos tecnológicos, XXIII(4). Universidade do Vale do Rio dos Sinos/CNPq, 50p. (1 mapa).

EMBRAPA (1999) Centro Nacional de Pesquisa de Solos. Sistema brasileiro de classificação de solos. Brasília. Embrapa Produção de Informação; Rio de Janeiro: Embrapa Solos, $412 \mathrm{p}$.

EMPRESA BRASILEIRA DE PESQUISA AGROPECUÁRIA (1999) Impacto Ambiental e Implicações Sócio-Econômicas da Agricultura Intensiva em Água Subterrânea. Embrapa, Jaguariúna, 26 p. (Relatório final de projeto).

EMPRESA BRASILEIRA DE PESQUISA AGROPECUÁRIA (2001) Uso agrícola das áreas de afloramento do Aqüifero Guarani e implicações na qualidade da água subterrânea. Embrapa, Jaguariúna, 22 p. (Relatório final de projeto). EPAGRI (1997) Zoneamento agroambiental. (Ed. CD-ROM). GOMES. M.A.F.; FILIZOLA, H.F.; SPADOTTO, C.A. (2002) Uso agrícola das áreas de recarga do Aqüifero Guarani e implicações na qualidade da água subterrânea. In: CONGRESSO BRASILEIRO DE SOJA E MERCOSOJA, 2. Londrina, Anais. Londrina, Embrapa Soja. p. 36-42. (Documentos/Embrapa Soja, $n^{\circ}$ 180).

GOMES, M. A. F.; SPADOTTO, C.; LANCHOTTE, V. L. (2001) Ocorrência do herbicida tebuthiuron na água subterrânea da microbacia do Córrego Espraiado, Ribeirão Preto - SP. Pesticidas: R. Ecotoxicol. e Meio Ambiente, v. 11. p. 65-76.

GOMES, M. A. F.; FILIZOLA, H.F.; MARIA DE PAULA, M.; DIOGO, A.; CERDEIRA, A. L. (2000) Áreas críticas nas porções de recarga do Aqǘfero Guarani localizadas nas nascentes do Rio Araguaia. Jaguariúna: Embrapa Meio Ambiente, 16p. (Embrapa Meio Ambiente. Documentos, 18).

GOMES, M. A .F.; NEVES, M.C.; SPADOTTO, C. A ; LUIZ, A J.B. (1996) Mapeamento expedito dos potenciais de infiltração e de escoamento superficial da água para os solos da microbacia do Córrego do Espraiado em Ribeirão Preto SP. In: CONGRESSO LATINO-AMERICANO DE CIÊNCIA DO SOLO, 13. Águas de Lindóia, 1996. Anais. Campinas, SBCS/ESALQ. 04 p (Editado em CD-ROM).

IAC. São Paulo (1991) Plano Cartográfico do Estado de São Paulo: carta pedológica do Estado de São Paulo - Ribeirão Preto. Campinas: IAC, esc. 1:100.000.

IAC. Dados meteorológicos. Estação de Ribeirão Preto. (Relatório de dados meteorológicos do período 1990-1998).

IAPAR. Caracterização da estrutura de produção agropecuária do 
Estado do Paraná. (Informe Técnico 01/2002). 01p.

IAPAR. Caracterização da estrutura de produção agropecuária do Estado do Paraná. (Informe Técnico 01/2002). 01p.

INSTITUTO DE PLANEJAMENTO E ECONOMIA AGRÍCOLA. Síntese anual de agricultura de Santa Catarina - 1998 1999. Florianópolis, 1999. 159p.

MINISTÉRIO DA AGRICULTURA (1973) Levantamento de reconhecimento dos solos do Estado do Rio Grande do Sul. Recife, 431p. (Boletim Técnico n. 30).

MIKLÓS, A . A. de W. ; GOMES, M.A .F. (1996) Levantamento semi-detalhado dos solos da Bacia Hidrográfica do Córrego do Espraiado, Ribeirão Preto - SP. Jaguariúna, 48 p. (Relatório de consultoria ).

PESSOA, M.C.P.Y.; GOMES, M .A. F.; DORNELAS DE SOUSA, M.; NICOLELLA, G.; CERDEIRA, A .L.; MONTICELLI, A . (1998) Simulação do movimento de herbicidas utilizados no monocultivo de cana-de-açúcar em Areia Quartzosa da área de recarga do Aqüífero Guarani em Ribeirão Preto, SP. Rev.Cient. Rural, v. 3,n. 2, p. 11-19.

PESSOA, M.C.P.Y.; GOMES, M A F.; DORNELAS DE SOUSA, M.; NICOLELLA, G.; CERDEIRA, A .L.; MONTICELLI, A . (1999) Simulação do movimento de herbicidas utilizados no monocultivo de cana-de-açúcar em Latossolo VermelhoEscuro da área de recarga do Aqüífero Guarani em Ribeirão Preto, SP. Rev. Cient. Rural, v. 4, n. 1; p. 15-24.

RADAMBRASIL. Ministério das Minas e Energia. Folhas das bordas da Bacia Sedimentar do Paraná (diversos volumes). 1983/1988.

RESENDE, M; CURI, N.; REZENDE, B.S.; CORRÊA, F.G. (1995) Pedologia: base para distinção de ambientes. Viçosa: NEPUT, 304p.

ROCHA, G.A. (1996) Mega reservatório de água subterrânea do Cone Sul: bases para uma política de desenvolvimento e gestão. UFPR/IDRC, Curitiba, 25 p. 